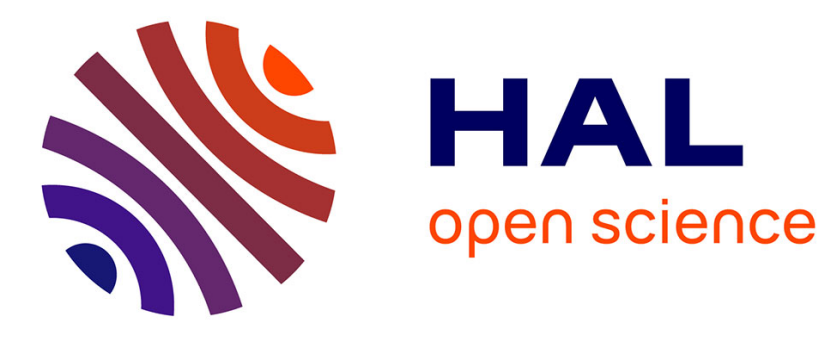

\title{
Modification of bone mineral density, bone geometry and volumetric BMD in young women with obesity
}

Laurent Maïmoun, Eric Renard, Ludovic Humbert, Safa Aouinti, Thibault

Mura, Vincent Boudousq, Patrick Lefebvre, Krishna Mahadea, Pascal

Philibert, Pascal de Santa Barbara, et al.

\section{To cite this version:}

Laurent Maïmoun, Eric Renard, Ludovic Humbert, Safa Aouinti, Thibault Mura, et al.. Modification of bone mineral density, bone geometry and volumetric BMD in young women with obesity. BONE, 2021, pp.116005. 10.1016/j.bone.2021.116005 . hal-03227555

\section{HAL Id: hal-03227555 \\ https://hal.science/hal-03227555}

Submitted on 16 Jun 2021

HAL is a multi-disciplinary open access archive for the deposit and dissemination of scientific research documents, whether they are published or not. The documents may come from teaching and research institutions in France or abroad, or from public or private research centers.
L'archive ouverte pluridisciplinaire HAL, est destinée au dépôt et à la diffusion de documents scientifiques de niveau recherche, publiés ou non, émanant des établissements d'enseignement et de recherche français ou étrangers, des laboratoires publics ou privés. 


\title{
Modification of bone mineral density, bone geometry and volumetric BMD in young women with obesity
}

\author{
Laurent Maïmoun ${ }^{\mathrm{a}, \mathrm{b}, *}$, Eric Renard ${ }^{\mathrm{c}, \mathrm{d}, \mathrm{e}}$, Ludovic Humbert ${ }^{\mathrm{f}}$, Safa Aouinti ${ }^{\mathrm{g}}$, Thibault Mura ${ }^{\mathrm{h}}$, \\ Vincent Boudousq ${ }^{\mathrm{i}}$, Patrick Lefebvre ${ }^{\mathrm{c}}$, Krishna Mahadea ${ }^{\mathrm{j}}$, Pascal Philibert ${ }^{\mathrm{k}}$, \\ Pascal de Santa-Barbara ${ }^{\mathrm{b}}$, Antoine Avignon ${ }^{1}$, Sébastien Guillaume ${ }^{\mathrm{m}}$, Ariane Sultan ${ }^{1}$, \\ David Nocca $^{\mathrm{n}}$, Denis Mariano-Goulart ${ }^{\mathrm{a}, \mathrm{b}}$
}

\author{
a Département de Médecine Nucléaire, Hôpital Lapeyronie, Centre Hospitalier Régional Universitaire (CHRU) Montpellier, Montpellier, France \\ ${ }^{\mathrm{b}}$ PhyMedExp, Université de Montpellier, INSERM, CNRS, Montpellier, France \\ ${ }^{\mathrm{c}}$ Departement d'Endocrinologie, Diabète, Nutrition, Hôpital Lapeyronie, CHRU Montpellier, Montpellier, France \\ d CIC INSERM 1001, Hôpital Gui de Chauliac, CHRU Montpellier, Montpellier cedex 5, France \\ e Institut de Génomique Fonctionnelle, CNRS UMR 5203/INSERM U661/Université Montpellier, Montpellier, France \\ ${ }^{\mathrm{f}}$ Musculoskeletal Unit, Galgo Medical, Barcelona, Spain \\ ${ }^{\mathrm{g}}$ Unité de Recherche Clinique et Epidémiologie, Hôpital Lapeyronie, CHRU Montpellier, Montpellier, France \\ ${ }^{\mathrm{h}}$ Unité de Recherche Clinique et Epidémiologie, Hôpital Carémeau, CHRU Nîmes, Nîmes, France \\ ${ }^{i}$ Département de Médecine Nucléaire, Hôpital Carémeau, CHRU Nîmes, Nîmes, France \\ ${ }^{\mathrm{j}}$ Université de Montpellier, France \\ ${ }^{\mathrm{k}}$ Département de Biochimie et d'Hormonologie, Hôpital Carémeau, CHRU Nîmes, Nîmes, France \\ ${ }^{1}$ Département Endocrinologie, Nutrition, Diabète, Equipe Nutrition, Diabète, CHRU Montpellier, Montpellier, France \\ m Département d'Urgence et Post-Urgence Psychiatrique, Hôpital Lapeyronie, CHRU Montpellier, UMI, INSERM U1061, 34295 Montpellier, France \\ " Département de Chirurgie Digestive, Hôpital St Eloi, CHRU Montpellier, Montpellier, France
}

\section{A R T I C L E I N F O}

\section{Keywords:}

Obesity

3D-DXA

3D-SHAPER(

Areal bone mineral density

Hip structural analysis (HSA)

\begin{abstract}
A B S T R A C T
Background: Most obese women with low-trauma fractures present normal areal bone mineral density (aBMD), suggesting that other bone parameters are more determinant for fracture risk in these patients.

Objectives: (i) Determine the effects of obesity in young women on areal bone mineral density (aBMD), bone geometry, strength, and volumetric BMD determined by advanced DXA-based methods; (ii) model the profiles of bone parameters for each population with age; and (iii) determine the factors related to body composition (i.e. lean tissue mass and fat mass) potentially implicated in the "bone adaptation" in the femoral region.

Subjects and methods: Two hundred and twenty adolescent and young women from 18 to 35 years old were enrolled in this study: 128 patients with obesity and 92 age-matched ( \pm 6 months) normal-weight controls. aBMD was determined with DXA, whereas hip geometry and strength parameters were assessed by hip structural analysis (HSA) and volumetric BMD by 3D-SHAPER $®$ software.

Results: Compared with controls, subjects with obesity presented significantly higher aBMD at all bone sites, but the difference was greater at hip compared with lumbar spine or radius. Bone size estimates (i.e. cortical thickness), as well as strength estimates (i.e. cross-sectional area) were higher at all femoral subregions including femoral neck, intertrochanteric region and femoral shaft in young women with obesity. In whole proximal femur and all femoral compartments, vBMD was also higher in subjects with obesity, but the difference between groups was greater for cortical vBMD compared with trabecular vBMD. When hip bone parameters were modelled for each group from individual values, maximal values were reached between 20 and 26 years in both groups but, whatever the age, subjects with obesity presented higher values than controls. In both groups, lean body mass (LBM) was the parameter most positively associated with the greatest number of bone parameters studied. Conclusion: Our study confirmed that young women with obesity presented higher aBMD, better hip geometry and greater strength compared with normal-weight controls. Additionally, cortical and trabecular compartments measured by 3D-SHAPER ${ }^{\circ}$ were favourably and concomitantly modified. However, it remains to be
\end{abstract}

\footnotetext{
* Corresponding author: Département de Biophysique, Université Montpellier, Service de Médecine Nucléaire, Hôpital Lapeyronie, 371, avenue du Doyen Gaston Giraud, 34295 Montpellier cedex 5, France.

E-mail address: 1-maimoun@chu-montpellier.fr (L. Maïmoun).
} 


\section{Introduction}

Peak bone mass (PBM) was shown to be an important determinant of the risk of future osteoporosis [4], and thus a better understanding of the factors underlying bone mass acquisition is crucial to help adolescents and young adults reach optimal bone mass.

A variety of diseases influence bone mass and, among them, obesity may improve areal bone mineral density (aBMD) [5,6]. More specifically, adolescents and young women with obesity present higher aBMD than normal-weight controls [7-9]. Our group confirmed the favourable effect of obesity on aBMD, highlighting that this phenomenon was not only accentuated by ageing, due to faster bone mass acquisition and a slower pace of bone loss, but also by obesity severity and sex [9,10]. An increase in body mass, which accentuates the mechanical loading on the skeleton, is assumed to be the major factor in the bone mass gain in this population [5], but the bone traits appear to scale more with lean body mass (LBM) than body weight or fat mass [9-11]. Indeed, bone is an adaptive tissue that has the capacity to modify its mass and microarchitecture in response to a mechanical stimulus [12]. This capacity may explain the accentuated aBMD gain with increases in the body mass index (BMI) at the hip, a weight-bearing bone site [10].

Paradoxically, however, obesity may also be associated with increased fracture risk in both children and adolescents [13,14]. Leonard et al. suggested that the observed aBMD increase, in absolute terms, in overweight children is probably not sufficient to overcome the significantly greater forces generated when an obese child falls [7]. Such observations also raise the question of whether the skeletal adaption due to obesity is consistent with the excess body weight. Thus, more research is now needed to identify the key biomechanical and functional parameters that determine bone strength and fracture risk in the young population and refine our knowledge of the risk factors that influence these parameters [15].

Dual energy x-ray absorptiometry (DXA) is the conventional tool for measuring aBMD. However, this technique is confounded by differences in bone size, and obesity is known to be associated with a modification in this parameter [16], suggesting a probable measurement bias specifically in this population. Moreover, most postmenopausal obese women with low-trauma fractures present normal aBMD at the hip and spine [17], indicating that other bone parameters may be more determinant for fracture risk in these patients. Studies using high-resolution peripheral quantitative computed tomography (HRpQCT) to compare volumetric BMD (vBMD) and bone microarchitecture between obese and lean children have indicated that bone strength does not appropriately increase in obese children, despite the increase in body weight $[18,19]$. Moreover, it may be reduced in the tibia, reflecting a negative impact of fat mass on bone strength in weight-bearing sites [18]. However, HRpQCT measurements are confined to the distal tibia and radius and thus may not reflect changes in other regions of the axial and appendicular skeleton, such as hip.

To overcome this limitation, advanced DXA-based methods have been developed. Hip structural analysis (HSA) estimates geometry and strength indices [20] and 3D modelling methods evaluate vBMD and differentiate trabecular and cortical compartments at the proximal femur. Several HSA and 3D-DXA-derived variables are highly correlated with equivalent measurements assessed by QCT [21,22].

The threefold aim of this study was to (i) compare areal bone mineral density (aBMD), HSA and 3D-DXA parameters in young women with obesity (OB) and controls (CON) around PBM; (ii) model the profiles of bone parameters for each population with age; and (iii) determine the factors related to body composition (i.e. lean tissue mass and fat mass) potentially implicated in the "bone adaptation" in the femoral region.

\section{Subjects and methods}

Study approval was obtained from the Regional Research Ethics Committee (Comité de Protection des Personnes Sud-Mediterranee IV, Montpellier, France; reference: 1102 03) and permission for the clinical trials was granted by the French Agency for the Safety of Health Products (Agence Française de Securite Sanitaire des Produits de Santé; AFSSAPS; reference: 2011-A00108-33). All participants gave written informed consent.

\subsection{Subjects}

Two hundred and twenty adolescents and young women with ages from 18 to 35 years were enrolled in this study. All were Caucasian. Women with obesity as defined by a BMI higher than $30 \mathrm{~kg} / \mathrm{m}^{2}$ were consecutively recruited in the Endocrinology Department of the University Hospital of Montpellier, France, between June 2014 and November 2019. All had been referred for metabolic and physical assessment of their obesity $(n=2)$ or for a check-up before bariatric surgery $(n=126)$. Patients were then classified into a group according to the grade of obesity using the World Health Organization (WHO) definition [5]: class I (BMI $30-34.9 \mathrm{~kg} / \mathrm{m}^{2}$ ), class II (BMI $35-39.9 \mathrm{~kg} / \mathrm{m}^{2}$ ), or class III (BMI $\geq 40 \mathrm{~kg} / \mathrm{m}^{2}$ ). The number of patients was, respectively, $n$ $=6$ for class I, $n=44$ for class II and $n=78$ for class III. Most of these patients had a longstanding history of obesity (more than 4 years) and none of the included patients had undergone bariatric surgery. Exclusion criteria were pregnancy, acute medical treatment, and physical handicap (amputation, neurological lesion, orthopaedic prosthesis) that might interfere with bone mass or body composition measurement. Moreover, patients with a body weight $>190 \mathrm{~kg}$ or height $>192.5 \mathrm{~cm}$ were also excluded due to limitations of the densitometry device. Medical history and current medications were obtained by questionnaire. The control group was recruited from the community by advertisement. It consisted of healthy normal-weight adolescents and young women with a body mass index (BMI) ranging from 18 to $24.9 \mathrm{~kg} / \mathrm{m}^{2}$. Individuals in the control group reported neither history of obesity, nor diabetes mellitus, hypertension or dyslipidaemia. All presented with normal menstrual cycles. Controls and patients were matched using an age-class frequency matching technique $(73 \%$ of subjects were $[18,25]$ years old, $22 \%$ were $[25,30]$ and $5 \%$ were $[30,35])$. No subject was taking a medication known to affect bone metabolism or presented with primary amenorrhoea. Physical activity levels were not specifically determined. Nevertheless, the control group consisted of subjects who performed only leisure physical activities for fewer than $1 \mathrm{~h}$ per week. None of the individuals with obesity were participating in a training program on the day of inclusion.

\subsection{Methods}

This study followed a case-control design. Standing height was measured with a stadiometer to the nearest $0.1 \mathrm{~cm}$. Weight was determined using a weight scale with a precision of $0.1 \mathrm{~kg}$. BMI was calculated as weight $(\mathrm{kg})$ divided by the square of height $(\mathrm{m})$.

\subsubsection{Medical and menstrual histories}

Each subject or her parents responded to a medical questionnaire designed to assess the general medical and menstrual history, with questions on the age of menarche and the presence of menstrual disorders. 


\subsubsection{Definition of comorbidities}

Comorbidities were defined according to the usual definitions: Type 2 diabetes (T2D) was defined as $\mathrm{HbA} 1 \mathrm{c} \geq 6.5 \%$ and/or fasting glycaemia $\geq 7 \mathrm{mmol} / \mathrm{l}$ and/or anti-diabetic treatment [14]. Hypertension was defined as systolic blood pressure $\geq 140$ and/or diastolic blood pressure $\geq 90$ and/or use of anti-hypertensive medications [15].

\subsubsection{Bone mineral density, body fat and lean body mass}

DXA (Hologic QDR-4500A, Hologic, Inc., Waltham, MA) measured aBMD $\left(\mathrm{g} / \mathrm{cm}^{2}\right)$ of the whole body and at specific bone sites: the anteroposterior lumbar spine (L1-L4), the dominant arm distal radius, and hip. The total and appendicular soft tissue body composition (fat mass [FM, kg], percentage of body fat mass [\% FM] and lean body mass [LBM, $\mathrm{kg}]$ ) were derived from the whole-body scan. Appendicular lean mass (ALM; $\mathrm{kg}$ ) was defined as the sum of the lean soft tissue mass of the arms and legs, as described by Heymfield et al. [22]. The skeletal muscle index (SMI; $\mathrm{kg} / \mathrm{m}^{2}$ ) was defined as ALM $/$ height ${ }^{2}$ [23]. All scanning and analyses were performed by the same operator to ensure consistency after following standard quality control procedures. Quality control for DXA was checked daily by scanning a lumbar spine phantom consisting of calcium hydroxyapatite embedded in a cube of thermoplastic resin (Hologic X-CALIBER Model DPA/QDR-1 anthropometric spine phantom). The CVs were $0.8 \%$ for spine and radius, $1.1 \%$ at the hip, and $<1 \%$ for LBM and FM.

\subsubsection{DXA-based $3 D$ modelling}

The 3D-Shaper software (version 2.2, Galgo Medical, Spain) [26] was used to assess the trabecular macrostructure and the cortex in 3D from DXA scans, at baseline and 6 and 12 months of follow-up. The method relies on a statistical shape and density model of the proximal femur built from a database of QCT images. The 3D statistical model is registered onto the DXA scan to obtain a 3D patient-specific model of the patient's proximal femur shape and BMD distribution. The cortical thickness and density are computed by fitting a mathematical function to the density profile computed along the normal vector at each node of the proximal femur surface mesh [31]. 3D-DXA measurements include the vBMD and bone mineral content (BMC) of the cortical, trabecular and integral (trabecular + cortical) bone compartments and the mean cortical thickness. The 3D-DXA measurements were performed at the total femur, neck, trochanter and shaft. The accuracy of the models and measurements provided by the 3D-DXA software algorithm was evaluated in a previous study by comparing 3D-DXA and QCT analyses [26].

\subsubsection{Bone geometry of the proximal femur}

Using DXA data, we analysed hip geometry parameters with HSA software [20]. The HSA program uses mineral mass and dimensional data from conventional DXA images of the hip to measure the structural dimensions of bone cross-sections corresponding to three thin regions traversing the proximal femur: the narrow-neck $(\mathrm{NN})$ region across the narrowest point of the femoral neck, the intertrochanteric (IT) region across the bisector of the neck and shaft axes, and the shaft region located at a distance 1.5 times the width of the femoral neck distal to the intersection of the neck and shaft axes. For each region, the HSA program computed the following variables: (i) the bone cross-sectional area (CSA; in square centimetres), an index of resistance to axial forces; (ii) the section modulus ( $Z$ ) (cubic centimetres), an index of strength in bending computed from the cross-sectional moment of inertia (iii) that weights the area in the cross-section by the square of its distance from the centroid (CSMI); (iv) the estimated average cortical thickness; and (v) the buckling ratio, an index of susceptibility to local cortical buckling under compressive loads. Higher values are associated with greater predicted femoral strength for all HSA-derived parameters except for $\mathrm{BR}$, for which higher values are predictive of inferior strength. HSA precision has not yet been assessed in children and adolescents; however, experience in mainly elderly populations has shown HSA precision on the order of $1 \%-5 \%$ for the HSA parameters at the three HSA regions
[23].

A single physician conducted the DXA acquisition and all 3D-DXA and HAS software analyses.

\subsubsection{Assays}

Blood samples $(25 \mathrm{ml})$ were collected in the morning (08 h30-09 h30) in sterile chilled tubes by standard venepuncture technique. The samples were allowed to clot at room temperature and were then centrifuged at $2500 \mathrm{rpm}$ for $10 \mathrm{~min}$ at $4{ }^{\circ} \mathrm{C}$. Serum intact parathyroid hormone (iPTH) and vitamin D were assayed by Cobas 6000 (Roche Diagnostic, Mannheim, Germany). The inter- and intra-assay coefficients of variation (CVs) for the parameters were lower than $7 \%$.

\section{Statistical analysis}

The characteristics of the patients are described with proportions for categorical variables and with means \pm standard deviations (SD) for quantitative variables. Comparisons between lean controls and patients with obesity were performed using Student's $t$-test for quantitative variables, or the Mann-Whitney $U$ test when the distribution of variables was non-Gaussian, and the Chi-square test for qualitative variables. To determine which parameters differed most between lean controls and obese patients, we calculated Cohen's d (difference between the means of the two groups divided by a pooled standard deviation) for each parameter, which is a standardized measure of the effect of a factor (here obesity) independent of the scale of the parameter under consideration [24]. As an indication, a Cohen's d of 0.2 corresponds to a small effect of the factor, 0.5 to a medium effect, 0.8 to a large effect, 1.2 to a very large effect, and 2 to a huge effect [25].

The relationship between age and the bone DXA-derived parameters at the femoral region was also analysed graphically in normal-weight controls and patients with obesity using thin plate regression spline models. The smoothing parameters were chosen by minimizing the generalized cross-validation function. The results are expressed graphically with the expected means and their 95\% Bayesian confidence intervals.

Finally, the relationships between anthropometric characteristics and bone parameters were analysed using Spearman's correlation coefficient.

Statistical analyses were performed at the conventional two-tailed $\alpha$ level of 0.05 using SAS version 9.4 (SAS Institute, Cary, NC).

\section{Results}

\subsection{Subject characteristics}

There was no significant difference in mean age and height between the control and obese groups (Table 1). In addition to the expected difference in weight, BMI, whole-body FM and LBM, and ALM and SMI were significantly greater in the obese group. Menarche had occurred significantly earlier in subjects with obesity (11.8 \pm 1.8 years) than controls $(12.8 \pm 1.3$ years, $p<0.01)$. Controls used more contraceptives than subjects with obesity. Concerning the hormonal profile, patients presented higher iPTH and lower vitamin D values compared with controls. The prevalence of fracture was comparable between groups. No fracture was defined as a fragility fracture.

\subsection{Comparison of bone mineral density between obese and control groups}

Table 2 presents the aBMD for the two groups at various bone sites. Compared with controls, subjects with obesity presented significantly ( $p$ $<0.01$ ) higher aBMD at all bone sites, but the difference was greater at the hip (Cohen's $\mathrm{d}=1.38$ ) compared with lumbar spine (Cohen's $\mathrm{d}=$ 0.654 ) or radius (Cohen's $d=1.19$ ). Concomitantly, the Z-score for aBMD was also higher in the young women with obesity at all bone sites, 
Table 1

Characteristics of normal-weight controls and patients with obesity matched for age

\begin{tabular}{|c|c|c|c|}
\hline Variables & $\begin{array}{l}\text { Control group ( } n= \\
\text { 92) }\end{array}$ & $\begin{array}{l}\text { OB group }(n= \\
128)\end{array}$ & $\begin{array}{l}p \text { - } \\
\text { Value }\end{array}$ \\
\hline Age, years & $23.3 \pm 3.1$ & $23.6 \pm 3.5$ & 0.70 \\
\hline Weight, kg & $60.2 \pm 7.5$ & $112.5 \pm 12.5$ & $<0.01$ \\
\hline Height, m & $1.66 \pm 0.06$ & $1.65 \pm 0.06$ & 0.24 \\
\hline BMI, $\mathrm{kg} / \mathrm{m}^{2}$ & $21.9 \pm 2.3$ & $41.5 \pm 4.2$ & $<0.01$ \\
\hline WB fat mass, $\mathrm{kg}$ & $17.4 \pm 4.2$ & $52.6 \pm 8.7$ & $<0.01$ \\
\hline WB fat mass, $\%$ & $28.7 \pm 4.6$ & $46.0 \pm 4.0$ & $<0.01$ \\
\hline WB lean tissue mass, kg & $40.7 \pm 4.7$ & $59.1 \pm 6.2$ & $<0.01$ \\
\hline $\begin{array}{l}\text { Appendicular lean tissue } \\
\text { mass, } \mathrm{kg}\end{array}$ & $17.5 \pm 2.4$ & $26.1 \pm 3.0$ & $<0.01$ \\
\hline $\begin{array}{l}\text { Skeletal muscle index, } \mathrm{kg} / \mathrm{m}^{2} \\
\text { Gynaecological profile }\end{array}$ & \multicolumn{2}{|c|}{ Gynaecological profile } & $<0.01$ \\
\hline Age of menarche, years & $12.8 \pm 1.3$ & $11.8 \pm 1.6$ & $<0.01$ \\
\hline $\begin{array}{l}\text { Use of contraceptives, nb } \\
\text { (\%) }\end{array}$ & $62(67.4)$ & $63(51.2)$ & $<0.01$ \\
\hline Fractures & $0.46 \pm 0.82$ & $0.42 \pm 1.26$ & 0.09 \\
\hline \multicolumn{4}{|l|}{ Hormonal profile } \\
\hline iPTH, ng/ml & $32.9 \pm 12.6$ & $46.1 \pm 17.7$ & $<0.01$ \\
\hline Vitamin $\mathrm{D}, \mathrm{ng} / \mathrm{ml}$ & $30.8 \pm 16.5$ & $21.3 \pm 9.6$ & $<0.01$ \\
\hline \multicolumn{4}{|l|}{ Comorbidities } \\
\hline Hypertension (number; \%) & - & $11(8.6 \%)$ & - \\
\hline Diabetes (number; \%) & - & $5(4.0)$ & - \\
\hline \multicolumn{4}{|l|}{ Treatments } \\
\hline Anti-hypertensive & & 3 & \\
\hline Anti-diabetes & & 4 & \\
\hline
\end{tabular}

Data are presented as mean \pm SD except for HTA and diabetes, which are presented as numbers and percentage (\%). BMI: body mass index; WB: whole body. iPTH: intact parathyroid hormone.

Table 2

Comparison of DXA bone parameters between normal-weight controls and patients with obesity matched for age.

\begin{tabular}{|c|c|c|c|c|}
\hline Variables & $\begin{array}{l}\text { Control group } \\
(\mathrm{n}=92)\end{array}$ & $\begin{array}{l}\text { OB group (n } \\
=128)\end{array}$ & $\begin{array}{l}\text { Cohen's } \\
\text { d }\end{array}$ & $\begin{array}{l}\text { p- } \\
\text { Value }\end{array}$ \\
\hline \multicolumn{5}{|l|}{ DXA bone parameters } \\
\hline $\begin{array}{l}\text { Whole-body aBMD } \\
\left(\mathrm{g} / \mathrm{cm}^{2}\right)\end{array}$ & $1.076 \pm 0.077$ & $\begin{array}{l}1.130 \pm \\
0.071\end{array}$ & 0.73 & $<0.01$ \\
\hline $\begin{array}{l}\text { Whole-body Z-score } \\
\text { (SD) }\end{array}$ & $-0.22 \pm 0.86$ & $0.31 \pm 0.88$ & 0.60 & $<0.01$ \\
\hline Hip aBMD $\left(\mathrm{g} / \mathrm{cm}^{2}\right)$ & $0.942 \pm 0.154$ & $\begin{array}{l}1.071 \pm \\
0.102\end{array}$ & 1.02 & $<0.01$ \\
\hline Hip Z-score (SD) & $-0.20 \pm 0.91$ & $0.96 \pm 0.8$ & 1.38 & $<0.01$ \\
\hline $\begin{array}{l}\text { Lumbar spine aBMD } \\
\left(\mathrm{g} / \mathrm{cm}^{2}\right)\end{array}$ & $0.992 \pm 0.112$ & $\begin{array}{l}1.058 \pm \\
0.092\end{array}$ & 0.66 & $<0.01$ \\
\hline $\begin{array}{l}\text { Lumbar spine Z- } \\
\text { score (SD) }\end{array}$ & $-0.31 \pm 1.03$ & $0.45 \pm 0.86$ & 0.82 & $<0.01$ \\
\hline $\begin{array}{l}\text { Radius aBMD (g/ } \\
\mathrm{cm}^{2} \text { ) }\end{array}$ & $0.551 \pm 0.039$ & $\begin{array}{l}0.598 \pm \\
0.041\end{array}$ & 1.19 & $<0.01$ \\
\hline Radius Z-score (SD) & $0.0 \pm 0.90$ & $1.69 \pm 1.03$ & 1.73 & $<0.01$ \\
\hline
\end{tabular}

Values are presented as mean $\pm \mathrm{SD}$. aBMD: areal bone mineral density; Z-score: the number of standard deviations above or below the mean for the patient's age, sex and ethnicity; SD: standard deviation.

ranging from 0.31 SD to 1.69 SD compared with the reference data.

\subsection{Comparison of bone HSA-derived femoral geometry parameters between obese and control groups}

Except for the endocortical diameter parameters at the intertrochanteric region and the femoral shaft, all HSA-derived parameters were statistically better ( $p=0.02$ to $p<0.01$ for all parameters) in the young women with obesity compared with normal-weight controls (Table 3). Thus, bone size estimates determined by cortical thickness and subperiosteal width and strength estimates determined by CSA, CSMI, section modulus and BR were improved at all femoral subregions including femoral neck, intertrochanteric region and femoral shaft in young women with obesity (Cohen's d ranging from 0.40 to 1.74 ).
Table 3

Comparison of HSA bone parameters between normal-weight controls and patients with obesity matched for age.

\begin{tabular}{|c|c|c|c|c|}
\hline Parameters & $\begin{array}{l}\text { Control } \\
\text { group }(\mathrm{n}= \\
\text { 92) }\end{array}$ & $\begin{array}{l}\text { OB group } \\
(\mathrm{n}=128)\end{array}$ & $\begin{array}{l}\text { Cohen's } \\
\text { d }\end{array}$ & $\begin{array}{l}\text { p- } \\
\text { Value }\end{array}$ \\
\hline Shaft neck angle $\left(^{\circ}\right)$ & $\begin{array}{l}128.97 \pm \\
5.86\end{array}$ & $\begin{array}{l}130.86 \pm \\
6.08\end{array}$ & 0.32 & 0.02 \\
\hline \multicolumn{5}{|l|}{$\begin{array}{l}\text { Narrowest part of the } \\
\text { femoral neck }\end{array}$} \\
\hline $\begin{array}{l}\text { Cross-sectional area (CSA; } \\
\mathrm{cm}^{2} \text { ) }\end{array}$ & $2.95 \pm 0.44$ & $3.67 \pm 0.39$ & 1.74 & $<0.01$ \\
\hline $\begin{array}{l}\text { Cross-sectional moment } \\
\text { of inertia (CSMI; } \mathrm{cm}^{4} \text { ) }\end{array}$ & $2.30 \pm 0.61$ & $3.02 \pm 0.58$ & 1.22 & $<0.01$ \\
\hline Section modulus $\left(\mathrm{Z} ; \mathrm{cm}^{3}\right)$ & $1.38 \pm 0.28$ & $1.70 \pm 0.28$ & 1.17 & $<0.01$ \\
\hline $\begin{array}{l}\text { Endocortical diameter } \\
(\mathrm{cm})\end{array}$ & $2.77 \pm 0.26$ & $2.91 \pm 0.31$ & 0.50 & $<0.01$ \\
\hline Buckling ratio & $8.96 \pm 1.85$ & $8.19 \pm 1.95$ & 0.40 & $<0.01$ \\
\hline $\begin{array}{l}\text { Mean cortical thickness } \\
(\mathrm{cm})\end{array}$ & $0.19 \pm 0.03$ & $0.23 \pm 0.03$ & 1.15 & $<0.01$ \\
\hline Subperiosteal width (mm) & $3.15 \pm 0.24$ & $3.37 \pm 0.27$ & 0.83 & $<0.01$ \\
\hline \multicolumn{5}{|l|}{ Intertrochanteric region } \\
\hline $\begin{array}{l}\text { Cross-sectional area (CSA; } \\
\left.\mathrm{cm}^{2}\right)\end{array}$ & $5.32 \pm 0.80$ & $6.25 \pm 0.9$ & 1.07 & $<0.01$ \\
\hline $\begin{array}{l}\text { Cross-sectional moment } \\
\left.\text { of inertia (CSMI; } \mathrm{cm}^{4}\right)\end{array}$ & $14.14 \pm 3.39$ & $\begin{array}{l}17.00 \pm \\
4.45\end{array}$ & 0.71 & $<0.01$ \\
\hline Section modulus $\left(\mathrm{Z} ; \mathrm{cm}^{3}\right)$ & $4.47 \pm 0.81$ & $5.21 \pm 1.09$ & 0.75 & $<0.01$ \\
\hline $\begin{array}{l}\text { Endocortical diameter } \\
(\mathrm{cm})\end{array}$ & $4.65 \pm 0.44$ & $4.77 \pm 0.55$ & 0.23 & 0.25 \\
\hline Buckling ratio & $7.35 \pm 2.01$ & $6.61 \pm 1.08$ & 0.48 & $<0.01$ \\
\hline $\begin{array}{l}\text { Mean cortical thickness } \\
(\mathrm{cm})\end{array}$ & $0.44 \pm 0.07$ & $0.50 \pm 0.07$ & 0.78 & $<0.01$ \\
\hline Subperiosteal width (mm) & $5.54 \pm 0.44$ & $5.76 \pm 0.54$ & 0.45 & $<0.01$ \\
\hline \multicolumn{5}{|l|}{ Femoral shaft } \\
\hline $\begin{array}{l}\text { Cross-sectional area (CSA; } \\
\mathrm{cm}^{2} \text { ) }\end{array}$ & $4.08 \pm 0.57$ & $4.82 \pm 0.58$ & 1.29 & $<0.01$ \\
\hline $\begin{array}{l}\text { Cross-sectional moment } \\
\text { of inertia }\left(\mathrm{CSMI} ; \mathrm{cm}^{4}\right)\end{array}$ & $3.11 \pm 0.78$ & $4.05 \pm 0.99$ & 1.03 & $<0.01$ \\
\hline Section modulus $\left(\mathrm{Z} ; \mathrm{cm}^{3}\right)$ & $2.08 \pm 0.40$ & $2.56 \pm 0.46$ & 1.09 & $<0.01$ \\
\hline $\begin{array}{l}\text { Endocortical diameter } \\
(\mathrm{cm})\end{array}$ & $1.75 \pm 0.31$ & $1.79 \pm 0.31$ & 0.14 & 0.74 \\
\hline Buckling ratio & $2.70 \pm 0.50$ & $2.53 \pm 0.49$ & 0.35 & $<0.01$ \\
\hline $\begin{array}{l}\text { Mean cortical thickness } \\
(\mathrm{cm})\end{array}$ & $0.56 \pm 0.09$ & $0.64 \pm 0.09$ & 0.85 & $<0.01$ \\
\hline Subperiosteal width (mm) & $2.86 \pm 0.31$ & $3.07 \pm 0.22$ & 0.77 & $<0.01$ \\
\hline
\end{tabular}

Values are presented as mean \pm SD.

\subsection{Comparison of 3D-DXA bone parameters between obese and control groups}

The comparison of 3D-DXA parameters is presented in Table 4. Young women with obesity had significantly higher 3D-DXA-derived parameters ( $p<0.01$ for all) in whole proximal femur and at all femoral compartments compared with controls. For the whole proximal femur, the Cohen's d values were 0.96 for integral vBMD, 0.53 for trabecular vBMD, and 1.26 for cortical vBMD. When femoral subregion analysis was performed, the effect of obesity on vBMD parameters was more marked at the trochanter region compared with neck and shaft regions. In whole proximal femur and in all femoral compartments, the difference between groups was greater for cortical vBMD compared with trabecular vBMD. The mean cortical thickness was also significantly greater $(p<0.01)$ in young patients with obesity compared with controls for whole proximal femur (Cohen's $d=1.16$ ) and all femoral subregions (Cohen's $d=0.41$ for neck, 0.89 for trochanter and 1.02 for shaft).

\subsubsection{Bone parameters according to the class of obesity}

When bone parameters were analysed according to the severity of obesity, no difference was observed between classes of obesity for aBMD, HSA or 3D-DXA-derived parameters (Supplemental Table 1). 
Table 4

Comparison of 3D-DXA bone parameters between normal-weight controls and patients with obesity matched for age.

\begin{tabular}{|c|c|c|c|c|}
\hline Variables & $\begin{array}{l}\text { Control group } \\
(\mathrm{n}=92)\end{array}$ & $\begin{array}{l}\text { OB group ( } \mathrm{n} \\
=128)\end{array}$ & $\begin{array}{l}\text { Cohen's } \\
\text { d }\end{array}$ & $\begin{array}{l}\text { p- } \\
\text { Value }\end{array}$ \\
\hline \multicolumn{5}{|l|}{ Total proximal femur } \\
\hline $\begin{array}{l}\text { Integral vBMD (mg/ } \\
\left.\mathrm{cm}^{3}\right)\end{array}$ & $350.3 \pm 48.5$ & $394.4 \pm 44.1$ & 0.96 & $<0.01$ \\
\hline $\begin{array}{l}\text { Trabecular vBMD } \\
\left(\mathrm{mg} / \mathrm{cm}^{3}\right)\end{array}$ & $216.8 \pm 38.7$ & $237.3 \pm 38.8$ & 0.53 & $<0.01$ \\
\hline $\begin{array}{l}\text { Cortical vBMD (mg/ } \\
\left.\mathrm{cm}^{3}\right)\end{array}$ & $820.4 \pm 45.6$ & $869.5 \pm 33.8$ & 1.26 & $<0.01$ \\
\hline $\begin{array}{l}\text { Mean cortical } \\
\text { thickness }(\mathrm{mm})\end{array}$ & $1.89 \pm 0.15$ & $2.10 \pm 0.20$ & 1.16 & $<0.01$ \\
\hline \multicolumn{5}{|l|}{ Neck region } \\
\hline $\begin{array}{l}\text { Integral vBMD (mg/ } \\
\left.\mathrm{cm}^{3}\right)\end{array}$ & $436.2 \pm 65.1$ & $484.3 \pm 70.1$ & 0.71 & $<0.01$ \\
\hline $\begin{array}{l}\text { Trabecular vBMD } \\
\left(\mathrm{mg} / \mathrm{cm}^{3}\right)\end{array}$ & $292.9 \pm 52.2$ & $334.6 \pm 55.8$ & 0.77 & $<0.01$ \\
\hline $\begin{array}{l}\text { Cortical vBMD (mg/ } \\
\left.\mathrm{cm}^{3}\right)\end{array}$ & $848.9 \pm 69.1$ & $906.0 \pm 58.8$ & 0.90 & $<0.01$ \\
\hline $\begin{array}{l}\text { Mean cortical } \\
\text { thickness }(\mathrm{mm})\end{array}$ & $1.79 \pm 0.20$ & $1.89 \pm 0.29$ & 0.41 & $<0.01$ \\
\hline \multicolumn{5}{|l|}{ Trochanter region } \\
\hline $\begin{array}{l}\text { Integral vBMD (mg/ } \\
\left.\mathrm{cm}^{3}\right)\end{array}$ & $274.0 \pm 39.7$ & $320.9 \pm 42.1$ & 1.14 & $<0.01$ \\
\hline $\begin{array}{l}\text { Trabecular vBMD } \\
\left(\mathrm{mg} / \mathrm{cm}^{3}\right)\end{array}$ & $176.9 \pm 33.3$ & $211.2 \pm 34.3$ & 1.01 & $<0.01$ \\
\hline $\begin{array}{l}\text { Cortical vBMD (mg/ } \\
\left.\mathrm{cm}^{3}\right)\end{array}$ & $704.3 \pm 56.8$ & $771.0 \pm 51.8$ & 1.24 & $<0.01$ \\
\hline $\begin{array}{l}\text { Mean cortical } \\
\text { thickness }(\mathrm{mm})\end{array}$ & $1.91 \pm 0.16$ & $2.10 \pm 0.25$ & 0.89 & $<0.01$ \\
\hline \multicolumn{5}{|l|}{ Shaft region } \\
\hline $\begin{array}{l}\text { Integral vBMD (mg/ } \\
\left.\mathrm{cm}^{3}\right)\end{array}$ & $447.0 \pm 66.6$ & $505.5 \pm 55.4$ & 0.97 & $<0.01$ \\
\hline $\begin{array}{l}\text { Trabecular vBMD } \\
\left(\mathrm{mg} / \mathrm{cm}^{3}\right)\end{array}$ & $236.6 \pm 50.7$ & $272.9 \pm 46.9$ & 0.75 & $<0.01$ \\
\hline $\begin{array}{l}\text { Cortical vBMD (mg/ } \\
\left.\mathrm{cm}^{3}\right)\end{array}$ & $886.8 \pm 67.8$ & $935.7 \pm 43.8$ & 0.85 & $<0.01$ \\
\hline $\begin{array}{l}\text { Mean cortical } \\
\text { thickness }(\mathrm{mm})\end{array}$ & $2.90 \pm 0.24$ & $3.18 \pm 0.32$ & 1.02 & $<0.01$ \\
\hline
\end{tabular}

Values are presented as mean \pm SD. vBMD: volumetric bone mineral density.
4.4.2. Modelling of bone DXA-derived parameters determined at femoral region with age

When total hip aBMD, selected HSA parameters reflecting bone size (endocortical diameter) and strength estimates (cross-sectional moment of inertia and section modulus), and 3D-DXA parameters were modelled for each group from individual values (Fig. 1), we observed that maximal values were reached between 20 and 26 years in subjects with obesity and controls. More specifically, all the bone DXA-derived parameters were significantly higher in subjects with obesity than controls whatever the age.

\subsubsection{Correlation analysis between anthropometric characteristics and bone parameters}

Correlations with BMI, whole-body fat and lean body mass (LBM) were determined for hip aBMD and for HSA and 3D-DXA-derived parameters for the whole population (Table 5). Only data for the narrowest part of the femoral neck (NN) for HSA analysis and total femur for 3DDXA analysis are presented but results for other subregions presented similar results (data not shown). For the whole population, BMI, wholebody FM and LBM were positively correlated with all the bone parameters, except for the buckling ratio, which was negatively correlated. When subgroup analysis was performed, whole-body LBM systematically presented the strongest association with all the bone parameters except for the 3D-DXA parameters in patients with obesity, in whom no correlation was observed, as for BMI and whole-body FM.

\section{Discussion}

In this cross-sectional study in young women from 18 to 35 years old, we evaluated the effect of obesity on various bone parameters around PBM acquisition, a crucial period that affects the risk of subsequent fracture in the elderly. In these conditions, obesity was associated with a significant increase in aBMD, a conventional parameter measured by DXA, at partially loaded (i.e. radius) and loaded (i.e. hip) skeletal sites, and an improvement in $\mathrm{VBMD}$, bone geometry and bone strength at femoral regions determined by a DXA-based 3D modelling approach and HSA software, respectively. These related obesity bone adaptations might modify bone mechanical properties and consequently bone strength.

Our data concerning the aBMD measurements are in line with
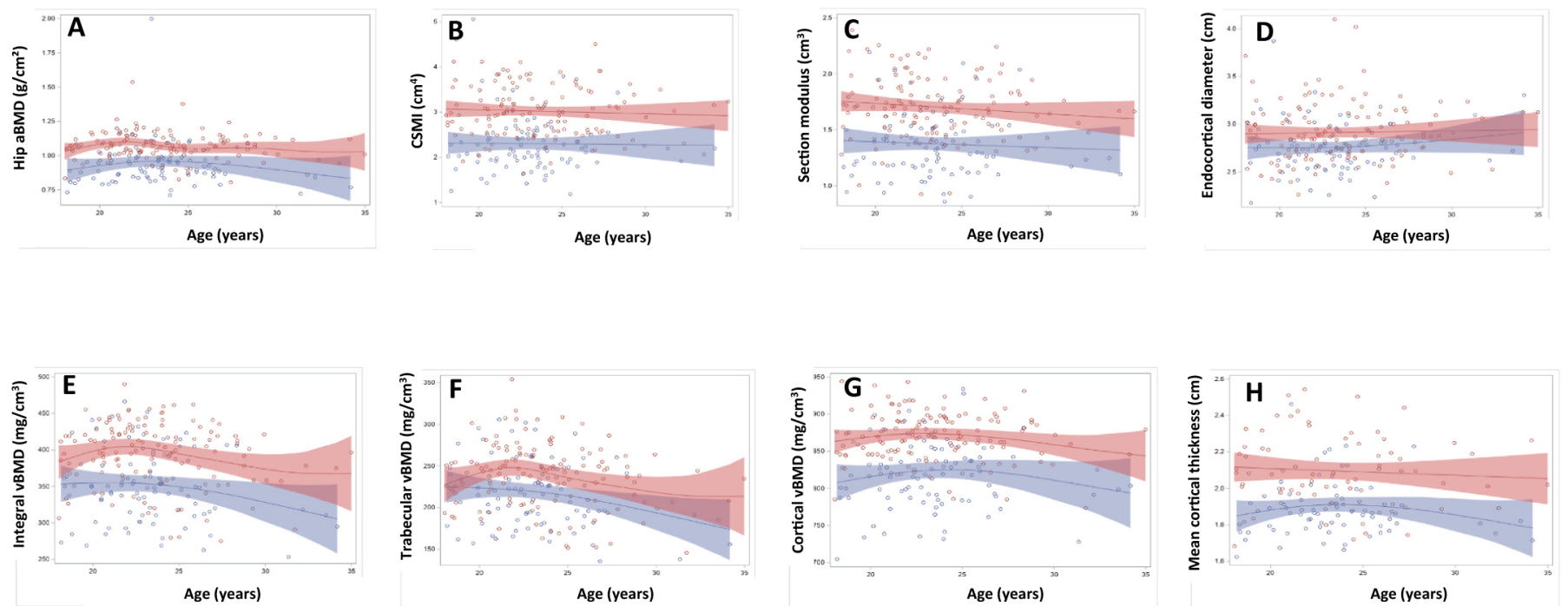

Fig. 1. Modelling of femoral DXA-derived parameters with age; A: hip areal bone mineral density (aBMD); hip structural parameters (HSA); B: cross-sectional moment of inertia (CSMI); C: section modulus; lumbar spine; D: endocortical diameter and 3D-DXA parameters for total proximal femur; E: integral volumetric bone mineral density (vBMD); F: trabecular vBMD; G: cortical vBMD; H: mean cortical thickness in controls (red) and in patients with obesity (blue). The dashed curves with the same colour represent the $95 \%$ confidence intervals. (For interpretation of the references to colour in this figure legend, the reader is referred to the web version of this article.) 
Table 5

Spearman's correlation coefficients between body composition and bone parameters in the whole population, normal-weight controls and patients with obesity.

\begin{tabular}{|c|c|c|c|c|c|c|c|}
\hline & & \multicolumn{2}{|l|}{ BMI } & \multicolumn{2}{|l|}{ WB LTM } & \multicolumn{2}{|l|}{ WB FM } \\
\hline & & $\mathrm{r}$ & p-Value & $\mathrm{r}$ & p-Value & $\mathrm{r}$ & p-Value \\
\hline \multirow{3}{*}{ aBMD } & Whole population & & & & & & \\
\hline & Hip & 0.583 & $<0.0001$ & 0.641 & $<0.0001$ & 0.538 & $<0.0001$ \\
\hline & CSA & 0.639 & $<0.0001$ & 0.714 & $<0.0001$ & 0.676 & $<0.0001$ \\
\hline \multirow{5}{*}{ HSA parameters (Narrowest part of the femoral neck) } & CSMI & 0.545 & $<0.0001$ & 0.712 & $<0.0001$ & 0.579 & $<0.0001$ \\
\hline & $\mathrm{Z}$ & 0.489 & $<0.0001$ & 0.655 & $<0.0001$ & 0.540 & $<0.0001$ \\
\hline & ED & 0.266 & $<0.0001$ & 0.388 & $<0.0001$ & 0.245 & 0.0003 \\
\hline & $\mathrm{BR}$ & -0.179 & $<0.0001$ & -0.154 & 0.0239 & -0.216 & 0.014 \\
\hline & MCt & 0.470 & $<0.0001$ & 0.479 & $<0.0001$ & 0.503 & $<0.0001$ \\
\hline \multirow{5}{*}{3 D-DXA parameters (total femur) } & Sw & 0.424 & $<0.0001$ & 0.554 & $<0.0001$ & 0.413 & $<0.0001$ \\
\hline & Integral vBMD & 0.462 & $<0.0001$ & 0.412 & $<0.0001$ & 0.421 & $<0.0001$ \\
\hline & Trabecular vBMD & 0.316 & $<0.0001$ & 0.261 & $<0.0001$ & 0.282 & $<0.0001$ \\
\hline & Cortical vBMD & 0.477 & $<0.0001$ & 0.537 & $<0.0001$ & 0.461 & $<0.0001$ \\
\hline & Mean cortical thickness & 0.570 & $<0.0001$ & 0.611 & $<0.0001$ & 0.542 & $<0.0001$ \\
\hline \multirow{3}{*}{ aBMD } & Controls & & & & & & \\
\hline & Hip & 0.377 & 0.0002 & 0.576 & $<0.0001$ & 0.190 & 0.0703 \\
\hline & CSA & 0.394 & 0.0001 & 0.610 & $<0.0001$ & 0.342 & 0.0009 \\
\hline \multirow{5}{*}{ HSA parameters (Narrowest part of the femoral neck) } & CSMI & 0.400 & $<0.0001$ & 0.693 & $<0.0001$ & 0.343 & 0.0009 \\
\hline & $\mathrm{Z}$ & 0.332 & 0.001 & 0.628 & $<0.0001$ & 0.318 & 0.0021 \\
\hline & ED & 0.174 & 0.098 & 0.387 & 0.0002 & 0.091 & 0.391 \\
\hline & $\mathrm{BR}$ & -0.069 & 0.518 & -0.037 & 0.7309 & -0.098 & 0.353 \\
\hline & MCt & 0.266 & 0.011 & 0.337 & 0.0011 & 0.227 & 0.031 \\
\hline \multirow{5}{*}{3 D-DXA parameters (total femur) } & Sw & 0.264 & 0.011 & 0.515 & $<0.0001$ & 0.149 & 0.159 \\
\hline & Integral vBMD & 0.274 & 0.008 & 0.292 & 0.005 & 0.170 & 0.107 \\
\hline & Trabecular vBMD & 0.225 & 0.031 & 0.286 & 0.006 & 0.117 & 0.268 \\
\hline & Cortical vBMD & 0.290 & 0.005 & 0.388 & 0.0001 & 0.119 & 0.260 \\
\hline & Mean cortical thickness & 0.312 & 0.005 & 0.517 & $<0.0001$ & 0.247 & 0.028 \\
\hline \multirow{3}{*}{ aBMD } & Patients with obesity & & & & & & \\
\hline & Hip & 0.200 & 0.024 & 0.318 & 0.0003 & 0.152 & 0.088 \\
\hline & CSA & 0.105 & 0.244 & 0.280 & 0.002 & 0.258 & 0.036 \\
\hline \multirow{6}{*}{ HSA parameters (Narrowest part of the femoral neck) } & CSMI & 0.072 & 0.421 & 0.470 & $<0.0001$ & 0.182 & 0.043 \\
\hline & $\mathrm{Z}$ & -0.035 & 0.701 & 0.373 & $<0.0001$ & 0.133 & 0.139 \\
\hline & ED & 0.110 & 0.220 & 0.330 & 0.0002 & 0.070 & 0.439 \\
\hline & $\mathrm{BR}$ & 0.081 & 0.366 & 0.136 & 0.130 & -0.029 & 0.751 \\
\hline & MCt & -0.002 & 0.978 & -0.002 & 0.980 & 0.133 & 0.138 \\
\hline & Sw & 0.132 & 0.141 & 0.383 & $<0.0001$ & 0.124 & 0.167 \\
\hline \multirow{4}{*}{3 D-DXA parameters (total femur) } & Integral vBMD & 0.149 & 0.093 & -0.025 & 0.784 & 0.089 & 0.318 \\
\hline & Trabecular vBMD & 0.130 & 0.142 & -0.054 & 0.550 & 0.0944 & 0.291 \\
\hline & Cortical vBMD & -0.066 & 0.461 & 0.063 & 0.483 & -0.031 & 0.729 \\
\hline & Mean cortical thickness & 0.241 & 0.042 & 0.188 & 0.116 & 0.164 & 0.171 \\
\hline
\end{tabular}

Data are presented as coefficients of correlation and p-values. aBMD: areal bone mineral density; HSA: hip structural analysis; CSA: cross-sectional area; CSMI: crosssectional moment of inertia; ED: endocortical diameter; BR: buckling ratio; MCt: mean cortical thickness; SW: subperiosteal width; vBMD: volumetric bone mineral density.

previous studies performed in adolescents and pre- and postmenopausal women with obesity, with these studies mainly reporting higher aBMD, particularly at weight-bearing bone sites such as the hip [7-10,26-29]. Based on a modelling approach, our group recently reported that obesity in young women from 16 to 27 years old induced a specific aBMD gain and bone remodelling profile characterized by a concomitant suppression of bone formation and resorption [9].

Our results based on HSA measurement suggested that obesity improved not only aBMD, but also size (cortical thickness, subperiosteal width) and strength estimates (CSA, CSMI, section modulus, BR). Previously, Bachmann et al. [26] reported in a group of women with similar age that proximal femur geometry assessed by the same HSA-derived parameters was also superior in the overweight/obese group compared with a lean control group. Other studies in adolescents [30] and pre- [31] and postmenopausal [11,32] women also reported an improvement in hip structure in absolute terms in response to increasing BMI. Nevertheless, femur strength appeared reduced relative to BMI in women with obesity $[11,32]$, suggesting that hip geometry might not be sufficient to compensate for fall forces that increase with body weight, therefore putting these patients at high risk of fracture in the femoral region. However, various studies [11,32] and a meta-analysis [33] reported that overweight and obese women had a lower risk of hip fractures than normal-weight women, even after BMD adjustment. Backman et al. [26] underlined that the risk of fracture is not only associated with bone geometry, but also with other components related to obesity, such as soft tissue padding that might modulate this risk. Finally, when the cushioning effects from trochanteric soft tissue were used to calculate an estimated risk of fracture, taking into account the force applied to the hip in a sideways fall from standing height with respect to femur strength, women with overweight/obesity appeared better protected that lean controls against hip fracture [26]. Previously, Beck et al. [11] had highlighted the likely favourable effect of the thicker soft tissue padding that reduces the force transmitted to the bone. Moreover, the modification in the quantity and the repartition of the soft tissues may help explain the reported site-specific fracture risk differences in obesity not explained by BMD; obese women tend to fracture less at skeletal sites with more soft tissue padding, including the hip, and tend to fracture more frequently at sites with less soft tissue padding, such as the humerus [26].

This is the first study to address the relationships between obesity and trabecular and cortical bone compartments using a 3D-DXA modelling approach in a large group of young women. Our results demonstrated a specific pattern of bone adaption to this pathology characterized by higher trabecular and cortical vBMD resulting in higher integral vBMD in patients with obesity compared with normal-weight controls. Moreover, the difference between the two groups for integral 
vBMD and aBMD at the femur presented a comparable magnitude (Cohen's $\mathrm{d}=0.96$ and 1.02, respectively). Concomitantly, cortical thickness was also improved. Nevertheless, when the data were analysed in greater detail, the effect of excessive weight appeared predominant in the cortical (Cohen's $\mathrm{d}=1.26$ ) compared to trabecular (Cohen's $\mathrm{d}=$ 0.53) compartments. It appeared, however, that the magnitude differences for the two compartments between the two groups were not homogeneous at the femur, and the trochanteric region appeared particularly responsive compared with the neck and shaft regions. The anabolic effect of obesity on specific regions of the femur (i.e. trochanter) may be modulated by the proportion of trabecular/cortical bone and by the different localizations which do not undergo the same increase in mechanical strains induced by overweight. Conversely to our results, in other situations of increasing or reducing the mechanical load applied to the skeleton, as during physical exercise or with spinal cord injury, respectively $[34,35]$, the trabecular compartment evaluated by the same 3D device seemed more responsive than the cortical compartment. The apparent difference between our and previous results concerning the preferential effect of mechanical loading on trabecular or cortical compartments is due to the different mathematical approaches, including Cohen's d or the percentage of difference. This last approach cannot take into account the difference in vBMD between cortical bone (mean value $\geq 800 \mathrm{mg} / \mathrm{cm}^{3}$ ) and trabecular bone (mean value $\geq 200$ $\mathrm{mg} / \mathrm{cm}^{3}$ ). In our study, when the percentage difference was calculated between patients with obesity and controls, a preferential effect on trabecular vBMD (9.5\%) compared with cortical vBMD (6\%) was also observed (data not shown).

In the absence of comparable data obtained from patients with obesity using the same 3D-DXA method, we can only try to draw parallels with the findings obtained with validated devices in comparable populations of patients. Nevertheless, it should be noted that, given the technical constraints, only the distal tibia can be analysed with PQCT or HR-pQCT, which might constitute a bias, most likely because the response of tibia and femur to biological or mechanical stimuli may partially differ, even though these two bones are both weight-bearing bones. In line with our results, however, significantly higher total tibia vBMD was also found in both young and pre- and postmenopausal women with obesity compared with women with normal BMI $[8,28,29,36]$. In these studies, the increase in total vBMD was mainly due to greater trabecular vBMD and cortical thickness, whereas cortical vBMD appeared less affected by obesity [8,28,29,36]. However, Evans et al. [36] and Sornay-Rendu et al. [29] also reported an improvement in cortical density (due to lower cortical porosity) only in postmenopausal women, suggesting that age and menopausal status may modulate the localized osteogenic response due to obesity. The increase in trabecular vBMD in the femoral region of our patients with obesity may be explained by a specific rearrangement and/or forms of trabeculae, which we unfortunately could not evaluate here. Also, HR-pQCT analysis revealed that the greater trabecular density is due to a reorganization of the trabeculae, characterized by greater trabecular numbers that reduce the trabecular separation $[18,19,36]$ associated with $[8,18,19]$ or without [36] lower trabecular thickness.

In this population of patients with obesity, as previously reported for HSA [37], it will be interesting to evaluate whether the incorporation of trabecular and cortical data in a model will improve the prediction of hip fracture risk in clinical practice, independently of aBMD. Our study performed in young women with obesity who are probably not at high risk of fragility fractures was not designed to answer this question. However, one element of response was given by a retrospective study that reported in a small number of subjects that postmenopausal women with hip fractures presented lower bone density at the trabecular compartment and the cortex compared with the non-fractured control group [38], confirming previous data obtained from pQCT [39].

In young women with obesity, the concomitant higher bone density (aBMD and vBMD) and improved bone geometry (i.e. cortical thickness) may explain the improved bone strength (i.e. CSA, CSMI, section modulus, BR) estimated by HSA analysis. Our results confirmed those of previous studies that reported a higher failure load (a strength estimate) in postmenopausal women [29] and in young women with obesity compared with controls [8]. Nevertheless, after adjusting for body weight, the failure load was lower in patients with obesity compared with controls [8]. Beck et al. [11] also reported that the higher evaluated bending strength did not remain in proportion to weight in the patients with obesity. Finally, Sornay-Rendu et al. [29] observed that the increase in all bone parameters in obese women was lower relative to the excess weight and the high BMI, which may explain a relative fragility.

The increase in body mass in obese patients is considered to be the major factor in the modification of bone characteristics to support localized mechanical loading applied on the skeleton [5]. However, these parameters are not sufficient to discriminate the real effect of the two principal components of the body characterized by LBM and FM. In our study, when the whole population or subgroup analysis was performed, LBM appeared to be more closely associated with bone parameters than FM. It should be noted that our observation has also been well-documented in women within a wide age and BMI spectrum, especially in the obese population [7,9-11,26,28,29,31]. For example, we recently reported that LBM was the parameter most consistently associated with aBMD in young women, whatever the BMI category, including normal-weight controls and patients with anorexia nervosa or obesity [9]. Interestingly, we report for the first time the same association between LBM and the trabecular and cortical compartments evaluated by 3D-DXA analysis. Previous studies performed with HR-pQCT observed that microarchitecture parameters of better bone quality were positively correlated with LBM, whereas those reflecting greater fragility were negatively correlated [29,40]. All these findings should confer a status of choice on LBM. Its precise evaluation and incorporation into risk scores may improve the detection of subjects at high risk of fracture. In addition to the anthropometric parameters, systemic biologically active molecules linked to obesity may also interact with bone metabolism and may explain the unexpectedly higher aBMD [9,10,27] and microarchitecture adaptations $[29,36]$ observed at the radius, a non-weight bearing bone site, in subjects with obesity. Among them, increased leptin levels [43,44], oestrogen secretion [29,45,46] and the more recently observed myokines (i.e. irisin) [27] may mediate the effect of obesity/LBM on bone tissue. In future research, it will be interesting to evaluate their potential relationships with integral, trabecular and cortical vBMD.

This study had limitations, particularly its cross-sectional design and the single measurements of bone parameters. However, these limitations are mitigated by the wide age range for the two groups around the time of peak bone mass, the high degree of age-matching, and the similar clinical profiles within groups. Moreover, the raw data associated with the data derived from modelling provide clear bone profiles for the two groups during the bone mass acquisition period. Longitudinal studies during weight loss in subjects with obesity may help to further clarify the concomitant effects of weight on aBMD, HSA and 3D-DXA parameters. We are aware that we did not evaluate the overall contribution of lifestyle factors to bone parameters, particularly physical activity, which may amplify the mechanical loading associated with excessive muscle mass and weight during movement on the skeleton in patients with obesity. However, the individuals with obesity and the healthy controls performed only leisure physical activities for less than $1 \mathrm{~h}$ per week and, as none of them was participating in a training program on the day of inclusion, this factor may have had a limiting effect. Moreover, Viljakainen et al. [47] using a multivariate model showed that the contribution of lifestyle factors to bone characteristics was minimal compared with BMI in patients with obesity.

In conclusion, this study showed that young women with obesity present higher aBMD and an improvement in hip geometry and strength parameters compared with normal-weight controls. Additionally, for the first time, we report that vBMD at cortical and trabecular compartments measured by $3 \mathrm{D}-\mathrm{SHAPER} \mathbb{R}$ are favourably and concomitantly modified. 
However, it now needs to be determined whether the evaluation of these new parameters improves the prediction of fracture risk, particularly in older women with obesity. Among the anthropometric parameters, LBM was most consistently associated with bone parameters, suggesting that this factor may have an important role in hip strength and thus in fracture risk.

\section{CRediT authorship contribution statement}

Laurent Maïmoun: Conceptualization, Methodology, Validation, Investigation, Resources, Data curation, Writing - original draft, Writing - review \& editing, Visualization, Supervision, Project administration, Funding acquisition. Eric Renard: Investigation, Writing - review \& editing. Ludovic Humbert: Software, Writing - review \& editing. Safa Aouinti: Methodology, Software, Validation, Formal analysis, Data curation, Writing - review \& editing, Visualization. Thibault Mura: Methodology, Software, Validation, Formal analysis, Data curation, Writing - review \& editing, Visualization. Vincent Boudousq: Investigation, Writing - review \& editing. Patrick Lefebvre: Investigation, Writing - review \& editing. Krishna Mahadea: Resources, Writing review \& editing. Pascal Philibert: Resources, Writing - review \& editing. Pascal de Santa-Barbara: Resources, Writing - review \& editing. Antoine Avignon: Investigation, Writing - review \& editing. Sébastien Guillaume: Investigation, Writing - review \& editing. Ariane Sultan: Investigation, Writing - review \& editing, Funding acquisition. David Nocca: Investigation, Writing - review \& editing, Funding acquisition. Denis Mariano-Goulart: Conceptualization, Investigation, Writing - original draft, Writing - review \& editing, Supervision, Project administration, Funding acquisition.

\section{Declaration of competing interest}

I certify that neither I nor my co-authors have a conflict of interest that is relevant to the subject matter or materials included in this work.

\section{Acknowledgments}

The authors would like to express their thanks to the subjects with obesity, the controls, and their parents for their participation. This work was supported by the CHRU of Montpellier (AOI UF 8751 and UF 8854).

\section{References}

[4] C.M. Weaver, C.M. Gordon, K.F. Janz, H.J. Kalkwarf, J.M. Lappe, R. Lewis, M. O'Karma, T.C. Wallace, B.C. Zemel, The National Osteoporosis Foundation's position statement on peak bone mass development and lifestyle factors: a systematic review and implementation recommendations Osteoporos Int 27(4) (2016) 1281-1386.

[5] S. Andersen, K.D. Frederiksen, S. Hansen, K. Brixen, J. Gram, R.K. Stoving, Bone structure and estimated bone strength in obese patients evaluated by highresolution peripheral quantitative computed tomography, Calcif. Tissue Int. 95 (1) (2014) 19-28.

[6] M.A. Bredella, M. Torriani, R.H. Ghomi, B.J. Thomas, D.J. Brick, A.V. Gerweck, L. M. Harrington, A. Breggia, C.J. Rosen, K.K. Miller, Determinants of bone mineral density in obese premenopausal women, Bone 48 (4) (2011) 748-754.

[7] M.B. Leonard, J. Shults, B.A. Wilson, A.M. Tershakovec, B.S. Zemel, Obesity during childhood and adolescence augments bone mass and bone dimensions, Am. J. Clin. Nutr. 80 (2) (2004) 514-523.

[8] V. Singhal, S. Sanchita, S. Malhotra, A. Bose, L.P.T. Flores, R. Valera, F.C. Stanford, M. Slattery, J. Rosenblum, M.A. Goldstein, M. Schorr, K.E. Ackerman, K.K. Miller, A. Klibanski, M.A. Bredella, M. Misra, Suboptimal bone microarchitecure in adolescent girls with obesity compared to normal-weight controls and girls with anorexia nervosa, Bone 122 (2019) 246-253.

[9] L. Maimoun, P. Garnero, T. Mura, D. Nocca, P. Lefebvre, P. Philibert, M. Seneque, L. Gaspari, F. Vauchot, P. Courtet, A. Sultan, M.L. Piketty, C. Sultan, E. Renard, S. Guillaume, D. Mariano-Goulart, Specific effects of anorexia nervosa and obesity on bone mineral density and bone turnover in young women, J. Clin. Endocrinol. Metab. 105 (4) (2020).
[10] L. Maimoun, T. Mura, E. Leprieur, A. Avignon, D. Mariano-Goulart, A. Sultan, Impact of obesity on bone mass throughout adult life: influence of gender and severity of obesity, Bone 90 (2016) 23-30.

[11] T.J. Beck, M.A. Petit, G. Wu, M.S. LeBoff, J.A. Cauley, Z. Chen, Does obesity really make the femur stronger? BMD, geometry, and fracture incidence in the women's health initiative-observational study, J. Bone Miner. Res. 24 (8) (2009) 1369-1379.

[12] H.M. Frost, The role of changes in mechanical usage set points in the pathogenesis of osteoporosis, J. Bone Miner. Res. 7 (3) (1992) 253-261.

[13] A. Goulding, A.M. Grant, S.M. Williams, Bone and body composition of children and adolescents with repeated forearm fractures, J. Bone Miner. Res. 20 (12) (2005) 2090-2096.

[14] K. Manias, D. McCabe, N. Bishop, Fractures and recurrent fractures in children; varying effects of environmental factors as well as bone size and mass, Bone 39 (3) (2006) 652-657.

[15] J.N. Farr, P. Dimitri, The impact of fat and obesity on bone microarchitecture and strength in children, Calcif. Tissue Int. 100 (5) (2017) 500-513.

[16] N.K. Pollock, E.M. Laing, C.A. Baile, M.W. Hamrick, D.B. Hall, R.D. Lewis, Is adiposity advantageous for bone strength? A peripheral quantitative computed tomography study in late adolescent females, Am. J. Clin. Nutr. 86 (5) (2007) $1530-1538$.

[17] M.O. Premaor, L. Pilbrow, C. Tonkin, R.A. Parker, J. Compston, Obesity and fractures in postmenopausal women, J. Bone Miner. Res. 25 (2) (2010) 292-297.

[18] P. Dimitri, R.M. Jacques, M. Paggiosi, D. King, J. Walsh, Z.A. Taylor, A.F. Frangi, N. Bishop, R. Eastell, Leptin may play a role in bone microstructural alterations in obese children, J. Clin. Endocrinol. Metab. 100 (2) (2015) 594-602.

[19] J.N. Farr, S. Amin, N.K. LeBrasseur, E.J. Atkinson, S.J. Achenbach, L.K. McCready, L. Joseph Melton III, S. Khosla, Body composition during childhood and adolescence: relations to bone strength and microstructure, J. Clin. Endocrinol. Metab. 99 (12) (2014) 4641-4648.

[20] T.J. Beck, C.B. Ruff, K.E. Warden, W.W. Scott Jr., G.U. Rao, Predicting femoral neck strength from bone mineral data. A structural approach, Investig. Radiol. 25 (1) (1990) 6-18.

[21] K. Ramamurthi, O. Ahmad, K. Engelke, R.H. Taylor, K. Zhu, S. Gustafsson, R. L. Prince, K.E. Wilson, An in vivo comparison of hip structure analysis (HSA) with measurements obtained by QCT, Osteoporos. Int. 23 (2) (2012) 543-551.

[22] L. Humbert, Y. Martelli, R. Fonolla, M. Steghofer, S. Di Gregorio, J. Malouf, J. Romera, L.M. Barquero, 3D-DXA: assessing the femoral shape, the trabecular macrostructure and the cortex in 3D from DXA images, IEEE Trans. Med. Imaging 36 (1) (2017) 27-39.

[23] B.C. Khoo, T.J. Beck, Q.H. Qiao, P. Parakh, L. Semanick, R.L. Prince, K.P. Singer, R. I. Price, In vivo short-term precision of hip structure analysis variables in comparison with bone mineral density using paired dual-energy X-ray absorptiometry scans from multi-center clinical trials, Bone 37 (1) (2005) $112-121$.

[24] J. Cohen, Statistical Power Analysis for the Behavioral Sciences, Routledge, New York, 1988, p. 567.

[25] S. Sawilowsky, New effect size rules of thumb, J. Mod. Appl. Stat. Methods 8 (2) (2009) 467-474.

[26] K.N. Bachmann, P.K. Fazeli, E.A. Lawson, B.M. Russell, A.D. Riccio, E. Meenaghan, A.V. Gerweck, K. Eddy, T. Holmes, M. Goldstein, T. Weigel, S. Ebrahimi, D. Mickley, S. Gleysteen, M.A. Bredella, A. Klibanski, K.K. Miller, Comparison of hip geometry, strength, and estimated fracture risk in women with anorexia nervosa and overweight/obese women, J. Clin. Endocrinol. Metab. 99 (12) (2014) 4664-4673.

[27] L. Maimoun, T. Mura, V. Attalin, A.M. Dupuy, J.P. Cristol, A. Avignon, D. MarianoGoulart, A. Sultan, Modification of muscle-related hormones in women with obesity: potential impact on bone metabolism, J. Clin. Med. 9 (4) (2020).

[28] D. Sukumar, Y. Schlussel, C.S. Riedt, C. Gordon, T. Stahl, S.A. Shapses, Obesity alters cortical and trabecular bone density and geometry in women, Osteoporos. Int. 22 (2) (2011) 635-645.

[29] E. Sornay-Rendu, S. Boutroy, N. Vilayphiou, B. Claustrat, R.D. Chapurlat, In obese postmenopausal women, bone microarchitecture and strength are not commensurate to greater body weight: the Os des Femmes de Lyon (OFELY) study, J. Bone Miner. Res. 28 (7) (2013) 1679-1687.

[30] M.A. Petit, T.J. Beck, J. Shults, B.S. Zemel, B.J. Foster, M.B. Leonard, Proximal femur bone geometry is appropriately adapted to lean mass in overweight children and adolescents, Bone 36 (3) (2005) 568-576.

[31] M. Schorr, L.E. Dichtel, A.V. Gerweck, M. Torriani, K.K. Miller, M.A. Bredella, Body composition predictors of skeletal integrity in obesity, Skelet. Radiol. 45 (6) (2016) 813-819.

[32] J. Shen, W.D. Leslie, C.M. Nielson, S.R. Majumdar, S.N. Morin, E.S. Orwoll, Associations of body mass index with incident fractures and hip structural parameters in a large Canadian cohort, J. Clin. Endocrinol, Metab. 101 (2) (2016) 476-484.

[33] C. De Laet, J.A. Kanis, A. Oden, H. Johanson, O. Johnell, P. Delmas, J.A. Eisman, H. Kroger, S. Fujiwara, P. Garnero, E.V. McCloskey, D. Mellstrom, L.J. Melton III, P. J. Meunier, H.A. Pols, J. Reeve, A. Silman, A. Tenenhouse, Body mass index as a predictor of fracture risk: a meta-analysis, Osteoporos. Int. 16 (11) (2005) 1330-1338.

[34] L. Freitas, T. Amorim, L. Humbert, R. Fonolla, A.D. Flouris, G.S. Metsios, A. Z. Jamurtas, Y. Koutedakis, Cortical and trabecular bone analysis of professional dancers using 3D-DXA: a case-control study, J. Sports Sci. 37 (1) (2019) 82-89.

[35] L. Gifre, L. Humbert, A. Muxi, L. Del Rio, J. Vidal, E. Portell, A. Monegal, N. Guanabens, P. Peris, Analysis of the evolution of cortical and trabecular bone 
compartments in the proximal femur after spinal cord injury by 3D-DXA, Osteoporos. Int. 29 (1) (2018) 201-209.

[36] A.L. Evans, M.A. Paggiosi, R. Eastell, J.S. Walsh, Bone density, microstructure and strength in obese and normal weight men and women in younger and older adulthood, J. Bone Miner. Res. 30 (5) (2015) 920-928.

[37] A.S. Karlamangla, E. Barrett-Connor, J. Young, G.A. Greendale, Hip fracture risk assessment using composite indices of femoral neck strength: the Rancho Bernardo study, Osteoporos. Int. 15 (1) (2004) 62-70.

[38] L. Humbert, A. Bague, S. Di Gregorio, R. Winzenrieth, X. Sevillano, M.A. Gonzalez Ballester, L. Del Rio, DXA-based 3D analysis of the cortical and trabecular bone of hip fracture postmenopausal women: a case-control study, J. Clin. Densitom. 23 (3) (2020) 403-410, https://doi.org/10.1016/j.jocd.2018.11.004.

[39] V.D. Bousson, J. Adams, K. Engelke, M. Aout, M. Cohen-Solal, C. Bergot, D. Haguenauer, D. Goldberg, K. Champion, R. Aksouh, E. Vicaut, J.D. Laredo, In vivo discrimination of hip fracture with quantitative computed tomography: results from the prospective European Femur Fracture Study (EFFECT), J. Bone Miner. Res. 26 (4) (2011) 881-893.

[40] E. Madeira, T.T. Mafort, M. Madeira, E.P. Guedes, R.O. Moreira, L.M. de Mendonca, I.C. Lima, P.R. de Pinho, A.J. Lopes, M.L. Farias, Lean mass as a predictor of bone density and microarchitecture in adult obese individuals with metabolic syndrome, Bone 59 (2014) 89-92.

[43] M.D. Kontogianni, U.G. Dafni, J.G. Routsias, F.N. Skopouli, Blood leptin and adiponectin as possible mediators of the relation between fat mass and BMD in perimenopausal women, J. Bone Miner. Res. 19 (4) (2004) 546-551.

[44] J.A. Pasco, M.J. Henry, M.A. Kotowicz, G.R. Collier, M.J. Ball, A.M. Ugoni, G. C. Nicholson, Serum leptin levels are associated with bone mass in nonobese women, J. Clin. Endocrinol. Metab. 86 (5) (2001) 1884-1887.

[45] I.R. Reid, Relationships among body mass, its components, and bone, Bone 31 (5) (2002) 547-555.

[46] M.A. Bredella, E. Lin, A.V. Gerweck, M.G. Landa, B.J. Thomas, M. Torriani, M. L. Bouxsein, K.K. Miller, Determinants of bone microarchitecture and mechanica properties in obese men, J. Clin. Endocrinol. Metab. 97 (11) (2012) 4115-4122.

[47] H.T. Viljakainen, H. Valta, M. Lipsanen-Nyman, T. Saukkonen, E. Kajantie, S. Andersson, O. Makitie, Bone characteristics and their determinants in adolescents and young adults with early-onset severe obesity, Calcif. Tissue Int. 97 (4) (2015) 364-375. 